\title{
Gastroesophageal reflux disease among population of Arar City, Northern Saudi Arabia
}

Anwar Matar Alsulobi ${ }^{1}$, Nagah Mohamed Abo el-Fetoh ${ }^{2}$, Sara Ghazi Eid Alenezi ${ }^{3}$, Razan Ahmed Alanazi ${ }^{3}$, Rawan Hamdan Salem Alenazy ${ }^{3}$, Fryail Aied Lafi Alenzy ${ }^{3}$, Amthal Alturqi Alenzi ${ }^{3}$, Aisha Melfy Al Hazmy ${ }^{3}$, Kholoud Obeid Albathaly ${ }^{3}$, Rehab Jazem Fattal Alruwaili ${ }^{4}$, Ibtisam Matan Alanazi ${ }^{3}$, Ebtihal Ahmad Ali Alghamdi $^{5}$, Maryam Saeed Alanazi ${ }^{1}$, Najah Owaed Aienzi ${ }^{3}$

${ }^{1}$ Intern, Faculty of Medicine, Northern Border University, Arar, Kingdom of Saudi Arabia

${ }^{2}$ Associate Professor of Public Health and Community Medicine, Faculty of Medicine, Northern Border University, Kingdom of Saudi Arabia

${ }^{3}$ Medical Student, Faculty of Medicine, Northern Border University, Arar, Kingdom of Saudi Arabia

${ }^{4}$ Dentistry Student, Dentistry Collage of Al-Jouf University, Al-Jouf Region, Kingdom of Saudi Arabia

${ }^{5}$ Intern, Faculty of Medicine, King Khalid University, Riyadh, Kingdom of Saudi Arabia

\section{Type of article: Original}

\begin{abstract}
Background: During the recent decade, several studies about prevalence of symptom-based GERD have revealed increase of its prevalence. In addition to the highly disturbing typical symptoms, it has a series of known consequences and may affect the quality of life.

Objective: To determine the prevalence of gastroesophageal reflux disease (GERD) as well as their main characteristics and risk factors among the population of Arar City, Northern Saudi Arabia.

Methods: A cross-sectional study was carried out on a sample of 302 individuals from population of Arar city from October 01, 2016 to May 30, 2017, using a researcher made questionnaire and checklist. The questionnaire was administrated in online method. Data were analyzed by SPSS version 22, using descriptive statistics and ChiSquare test.

Results: total prevalence of GERD among the studied respondents was $61.8 \%$. In $11.8 \%$ there was severe pain. Further, $61.8 \%$ reported loss of appetite as an associated condition, $57 \%$ reported nausea and vomiting, 55.9\% indigestion, $55.4 \%$ food regurgitation, $41.4 \%$ chest pain and $35.5 \%$ headache. The main found risk factors were fatty meals in $84.9 \%$ followed by coffee drinking in $77.4 \%$, stress in $71 \%$, spicy food in $58.1 \%$ NSAD in $24.7 \%$ and smoking in $17.2 \%$. There were no significant effect of sex, age, educational level, marital status or occupational status in the occurrence of GERD $(\mathrm{p}>0.05)$.

Conclusion: This is the first population-based study in Arar, Northern Saudi Arabia, reporting prevalence of GERD. The rate of $61.8 \%$ was substantially high. Coffee drinking, stress, spicy food, prolonged use of NSAID, fatty meals and smoking were the reported risk factors. Population-based endoscopic studies are recommended.

Keywords: Arar; Saudi Arabia; Prevalence; GERD; Risk factor
\end{abstract}

\section{Introduction}

The epidemiological aspects of gastroesophageal reflux disease (GERD) and heartburn have been a topic of growing interest in recent years because of its increasing prevalence and complications. Gastroesophageal reflux disease (GERD) broadly includes the whole spectrum of reflux disease, from intermittent symptoms like heartburn or acid regurgitation to endoscopic reflux esophagitis and Barrett's esophagus. Heart burn is a burning sensation in the central chest or upper central abdomen, the pain often rises in the chest and may radiate to the throat, neck, or angle of the jaw (1-3). It is also a definition of when stomach contents come back up into the esophagus resulting in either symptoms or complications $(4,5)$. Diagnosis and treatment of gastroesophageal reflux disease and heartburn is very

\section{Corresponding author:}

Anwar Matar A. Alsulobi, $173^{\text {rd }}$, King Faisal Street, the Old Airport Area, Arar City, Northern Border Province, Saudi Arabia. Tel.: +966559701469, E-mail: eidjojo1414@hotmail.com

Received: July 28, Accepted: September 06, 2017, Published: October 2017

iThenticate screening: September 06, 2017, English editing: September 22, 2017, Quality control: September 24, 2017 (C) 2017 The Authors. This is an open access article under the terms of the Creative Commons Attribution-NonCommercialNoDerivs License, which permits use and distribution in any medium, provided the original work is properly cited, the use is non-commercial and no modifications or adaptations are made. 
important because the disease, in addition to the highly disturbing typical symptoms, has a series of known consequences. It may affect the quality of life (6), decrease functional activity (7), increase health costs (8) and the risk of esophageal carcinoma in cases of Barrett's esophagus (9). The prevalence of heartburn in the population varies depending on whether the analysis is based on symptoms or signs of disease. It has been estimated that more than 15 million Americans suffer from heartburn once a day, and an additional 45 million experience heartburn at least once a month (10). In a study of thirteen Asian countries, a systematic review on epidemiology of GERD discovered that the reported population prevalence of gastroesophageal reflux disease ranged from $(2.5 \%)$ to $(6.7 \%)$ in eastern Asia, for at least weekly symptoms of heartburn and/or acid regurgitation, and may be on the increase. Age and the male population were the likely risk factors in that particular study. In China, the predominant extra esophageal manifestation of GERD is chest pain, whereas in Japan, association with asthma has been implicated in cases of severe esophagitis (11). Prevalence of GERD, in a study in North Bihar was reported at (23.6\%). Among males, the prevalence was (18\%) and among females, (30\%). The predominant symptom was heart burn with regurgitation. Poor socioeconomic status, the age group of 31 to 40 years and female gender were the associating aspects with this condition. A fatty and spicy diet, postprandial posture, and consumption of meat and tea were all found to be risk factors for gastroesophageal reflux disease (12). The aim of this research was to evaluate the prevalence of gastroesophageal reflux disease (GERD) as well as their main characteristics and risk factors among the population of Arar City, Northern Saudi Arabia.

\section{Material and Methods}

\subsection{Study design and participants}

A cross-sectional study was carried out on the population of Arar city, Northern Saudi Arabia. This study was conducted during the period from October 01, 2016 to May 30, 2017, using a researcher made questionnaire and checklist. The sample size was calculated using the sample size equation: $n=z^{2} p(1-p) / e^{2}$. Data was collected from 302 individuals aged between 18 to 75 years.

\subsection{Data collection}

Data were collected by using a researcher-made check list and a questionnaire that was administrated through online method. The questionnaire and checklist included questions designed to fulfill the study objectives. The questionnaire items were categorized into different parts: 1) socio-demographic characteristics including age, sex, educational level, marital status and occupational status, 2) questions about intensity of pain, increased food intake or not and other signs and symptoms of reflux, 3) questions about risk factors like smoking, coffee drinking, spicy food, alcohol and certain types of drugs (NSAID). We also asked whether there were any investigations done.

\subsection{Statistical Analysis}

All the data were analyzed using statistical package for social sciences (SPSS Inc.) version 20. Descriptive statistics for the prevalence and quantitative variables were used. A 2-sided p-value of less than 0.05 was considered statistically significant. We also used Chi-square text as the inferential statistics technique.

\subsection{Ethical considerations}

Permission to conduct the study was obtained from the Research and Ethics Committee at the College of Medicine, Northern Border University, Arar, Saudi Arabia. The questionnaire had a brief introduction explaining the aims and significance of the study.

\section{Results}

Table 1 shows the socio-demographic characteristics of the participants from Northern Saudi Arabia. The majority of the participants were females $(68.5 \%)$, the most common age group was $(18-25)$ years old, $(57.6 \%)$ were single and $(74.5 \%)$ were highly educated. About $(61.9 \%)$ of them were in employment. Regarding the prevalence of gastroesophageal reflux among the studied population in Arar city, 61.6\% (186) have had gastroesophageal reflux (GERD). Table 2 illustrates the characters, risk factors and treatment of gastroesophageal reflux among studied cases in Arar city, (21.5\%) described the pain as continuous, (34.4\%) as moderate and (11.8\%) as severe pain. Regarding associated conditions, (61.8\%) reported loss of appetite, (57\%) nausea and vomiting, (55.9\%) indigestion, (55.4) food regurgitation, (41.4\%) chest pain and (35.5\%) headache. Regarding predisposing factors, special meals was $(84.9 \%)$ followed by coffee drinking $(77.4 \%)$, stress $(71 \%)$, spicy food $(58.1 \%)$ and smoking (17.2\%). Treatment through use of antibiotics was (50\%). Table 3 illustrates the relationship between socio-demographic characters and gastroesophageal reflux among the studied population. There is no significant effect of sex, age, educational level, marital status or occupational status. 
Table 1. Socio-demographic characters of the studied population, Arar, Saudi Arabia

\begin{tabular}{|l|l|l|l|}
\hline Variables & $\mathrm{n}($ total=302) & $\%$ \\
\hline Sex & Female & 207 & 68.5 \\
\cline { 2 - 4 } & Male & 95 & 31.5 \\
\hline \multirow{4}{*}{ Age (years) } & $18-25$ & 162 & 53.6 \\
\cline { 2 - 4 } & $26-35$ & 84 & 27.8 \\
\cline { 2 - 4 } & $36-45$ & 38 & 12.6 \\
\cline { 2 - 4 } & $46-55$ & 12 & 4.0 \\
\cline { 2 - 4 } & $>55$ & 6 & 2.0 \\
\hline Educational level & Primary & 5 & 1.7 \\
\cline { 2 - 4 } & Secondary & 65 & 21.5 \\
\cline { 2 - 4 } & University or more & 225 & 74.5 \\
\cline { 2 - 4 } & Preparatory & 7 & 2.3 \\
\hline Marital status & Widowed & 2 & 37.6 \\
\cline { 2 - 4 } & Single & 174 & 38.4 \\
\cline { 2 - 4 } & Married & 116 & 34.1 \\
\cline { 2 - 4 } & Divorced & 10 & 187 \\
\hline Occupational status & Not employed & 187 & 12 \\
\cline { 2 - 4 } & Retired & 103 & \\
\cline { 2 - 4 } & Employed & & 3.0 \\
\hline
\end{tabular}

Table 2. Characteristics of gastroesophageal reflux in studied cases in Arar City, Saudi Arabia ( $\mathrm{n}=186)$

\begin{tabular}{|c|c|c|c|}
\hline \multicolumn{2}{|c|}{ Gastroesophageal reflux disease } & $\mathrm{n}$ & $\%$ \\
\hline \multirow[t]{3}{*}{ Severity of pain } & Sever & 22 & 11.8 \\
\hline & Mild & 64 & 34.4 \\
\hline & Moderate & 100 & 53.8 \\
\hline \multirow[t]{7}{*}{ Associated conditions and symptoms (there is overlapping) } & Headache & 66 & 35.5 \\
\hline & Regurgitation of food & 103 & 55.4 \\
\hline & Nausea and/or vomiting & 106 & 57.0 \\
\hline & Loss of appetite & 115 & 61.8 \\
\hline & Loss of weight & 46 & 24.7 \\
\hline & Indigestion & 104 & 55.9 \\
\hline & Chest pain & 77 & 41.4 \\
\hline \multirow[t]{8}{*}{ Predisposing factors (there is overlapping) } & Special meals (mainly fatty meals) & 158 & 84.9 \\
\hline & Spicy food & 108 & 58.1 \\
\hline & Smoking & 32 & 17.2 \\
\hline & Consumption & 7 & 3.8 \\
\hline & Psychic stress & 132 & 71.0 \\
\hline & Coffee drinking & 144 & 77.4 \\
\hline & Esophageal diseases & 24 & 12.9 \\
\hline & NSAD consumption & 46 & 24.7 \\
\hline \multirow[t]{2}{*}{ Treatment } & Antibiotics & 93 & 50.0 \\
\hline & Hospital admission & 71 & 38.2 \\
\hline \multirow[t]{4}{*}{ Previous investigations (if any) } & Gastroscopy & 17 & 9.1 \\
\hline & Barium meal & 13 & 7.0 \\
\hline & Ultrasound & 3 & 1.6 \\
\hline & Urea breath test & 6 & 3.2 \\
\hline
\end{tabular}


Table 3. Relationship between gastroesophageal reflux and socio-demographic characters of the studied population, Arar, Saudi Arabia

\begin{tabular}{|c|c|c|c|c|c|c|}
\hline \multirow{2}{*}{\multicolumn{2}{|c|}{ Variables }} & \multirow{2}{*}{\multicolumn{2}{|c|}{ Peptic ulcer; n (\%) }} & \multirow{4}{*}{$\begin{array}{l}\text { Total }(\mathrm{n}=302) ; \mathrm{n} \\
(\%) \\
207(68.5)\end{array}$} & \multirow{5}{*}{$\begin{array}{l}\text { Chi- } \\
\text { Square } \\
1.32\end{array}$} & \multirow{5}{*}{$\begin{array}{l}\mathrm{p}- \\
\text { value } \\
0.153\end{array}$} \\
\hline & & & & & & \\
\hline \multirow{3}{*}{ Sex } & & \multirow{2}{*}{$\begin{array}{l}\text { Yes } \\
(n=186) \\
132(71.0)\end{array}$} & \multirow{2}{*}{$\begin{array}{l}\text { No } \\
(n=116) \\
75(64.7)\end{array}$} & & & \\
\hline & Female & & & & & \\
\hline & Male & $54(29.0)$ & $41(35.3)$ & $95(31.5)$ & & \\
\hline \multirow{5}{*}{$\begin{array}{l}\text { Age group } \\
\text { (years) }\end{array}$} & $18-25$ & $91(48.9)$ & $71(61.2)$ & $162(53.6)$ & \multirow[t]{5}{*}{5.81} & \multirow[t]{5}{*}{0.213} \\
\hline & $26-35$ & $58(31.2)$ & $26(22.4)$ & $84(27.8)$ & & \\
\hline & $36-45$ & $27(14.5)$ & $11(9.5)$ & $38(12.6)$ & & \\
\hline & $46-55$ & $7(3.8)$ & $5(4.3)$ & $12(4.0)$ & & \\
\hline & $>55$ & $3(1.6)$ & $3(2.6)$ & $6(2.0)$ & & \\
\hline \multirow[t]{4}{*}{ Educational level } & Primary & $3(1.6)$ & $2(1.7)$ & $5(1.7)$ & \multirow[t]{4}{*}{0.66} & \multirow[t]{4}{*}{0.88} \\
\hline & Secondary & $42(22.6)$ & $23(19.8)$ & $65(21.5)$ & & \\
\hline & University & $136(73.1)$ & $89(76.7)$ & $225(74.5)$ & & \\
\hline & Preparatory & $5(2.7)$ & $2(1.7)$ & $7(2.3)$ & & \\
\hline \multirow[t]{3}{*}{ Marital status } & Single & $100(53.7)$ & $74(63.8)$ & $174(57.7)$ & \multirow[t]{3}{*}{5.42} & \multirow[t]{3}{*}{0.244} \\
\hline & Married & $76(40.9)$ & $40(34.5)$ & $116(38.4)$ & & \\
\hline & Divorced/widowed & $10(5.4)$ & $2(1.7)$ & $12(4.0)$ & & \\
\hline \multirow[t]{3}{*}{ Working status } & Not employed & $112(60.2)$ & $75(64.7)$ & $187(61.9)$ & \multirow[t]{3}{*}{1.24} & \multirow[t]{3}{*}{0.53} \\
\hline & Retired & $9(4.8)$ & $3(2.6)$ & $12(4.0)$ & & \\
\hline & Employed & 65 (34.9) & $38(32.8)$ & $103(34.1)$ & & \\
\hline
\end{tabular}

\section{Discussion}

This cross-sectional study was conducted to evaluate the prevalence of gastroesophageal reflux disease as well as its main characteristics and risk factors among the population of Arar city, Northern Saudi Arabia. This study shows high prevalence of GERD, generally (61.6\%). Our results were relatively high if compared to the Saudi study (13) which found that (15\%) of patients had GERD. An Indian study (14) found that prevalence of GERD was (22.2\%), which was much higher than in East Asia (15). Two studies in Tehran reported prevalence of (21.2\%) (16), (18.2\%) (17) and there was a presence of (12.3\%) in Kalaleh (18). In Brazil (19), GERD was found in (7.3\%). A study in Bihar (12) reported prevalence of GERD was (23.6\%). The prevalence of GERD in Iran ranged between $(6.3 \%$ $18.3 \%$ ) (20). Further, (61.8\%) reported loss of appetite as an associated condition, (57\%) reported nausea and vomiting, (55.9\%) indigestion, (55.4) food regurgitation, (41.4\%) chest pain and (35.5\%) headache. A study in Pakistan (21) reported that (84.38\%) of the cases reported dyspepsia, (45.28\%) reported anxiety, (10.27\%) restlessness and anxiety and (4.93\%) reported nightmares. A study in Southern India (14) found that most prevalent symptoms were heartburn $(26.4 \%)$, acid regurgitation $(18.1 \%)$ and night sleep disturbance $(10.2 \%)$. On the other hand, a study in China (22) found that regurgitation (10.8\%) was more prevalent than heartburn $(4.0 \%)$, $(8.7 \%)$ reported acid taste in the mouth, (5.3\%) unpleasant movement of material upwards from the stomach, (2.4\%) burning behind the breastbone and $(2.8 \%)$ for pain behind the breastbone. In medical check-up studies, the prevalence of GERD based on symptoms like heartburn or acid regurgitations at least once a week was $(5.0 \%-8.2 \%)$ (23-26). The occurrence of psychological distress with the symptoms of GERD has been observed in a study from Iran (23) where headaches, psychological distress, anxiety, nightmares and restlessness were common in GERD subjects. Regarding risk factors, our study results were, fatty meals (84.9\%) followed by coffee drinking (77.4\%), stress $(71 \%)$, spicy food $(58.1 \%)$ and smoking (17.2\%). A Pakistan study (21) reported risk factors as spicy meals $(69.81 \%)$ and raw onions (52.41\%), many (46.02\%) had a high BMI, smoking and regular use of NSAIDs were also among the prevalent risk factors. Lifestyle factors such as smoking (27) and use of NSAIDs (28) are known to be associated with GERD symptoms. Studies from Iran (29) and Europe (28) reported an association of GERD symptoms in subjects taking NSAIDs or aspirin. Our study agreed with studies which reported an association of current smoking and GERD symptoms in Indian (30) and British (27) subjects. Studies on Indian (31) and Iranian (29) populations observed an association between GERD symptoms and consumption of fried foods. Many studies did not find an association between cigarette smoking and the risk of GERD, as shown in studies conducted in Sweden (32), Spain (33) and the United States (34). A study in Bihar (12) reported risk factors as spicy diet. Our study did not find any significant correlation between GERD and sex, age, educational level, marital status or occupational status. Four cross sectional studies and one longitudinal study investigated the influence of sex on the prevalence of GERD symptoms; all five concluded that there was no significant association between sex and GERD 
$(27,28,32,35,36)$. Dietary and lifestyle modifications are considered the first line of treatment in patients with symptoms of GERD. Our investigations found that (50\%) of participants take antibiotics. A study in Pakistan (21) found that about half $(52.97 \%)$ of the patients were already using PPIs for treatment of GERD just prior to consultation, while physicians prescribed $96.75 \%$ of patients with PPIs at the time of consultation.

\section{Conclusions}

This study was the first population-based research in Arar, Northern Saudi Arabia reporting prevalence of GERD. The rate of $61.8 \%$ was substantially high. Coffee drinking, stress, spicy food, prolonged use of NSAID, fatty meals and smoking were the reported risk factors. Population-based endoscopic studies are recommended. Organization of community level awareness programs are recommended. Healthcare providers must be aware of community perceptions and practices.

\section{Acknowledgments:}

The success and final outcome of this work required the support and assistance of many people and we are fortunate to have gotten this throughout the completion of the work. My thanks go to Dr. Nagah Mohamed Abo El-Fetoh (associate professor of Community Medicine, NBU) and ALTARFAWI, KHULUD AWAD S, ALANAZI, RAED KHALID R (Students, Faculty of Medicine NBU) for their help in different steps of the research.

\section{Conflict of Interest:}

There is no conflict of interest to be declared.

Authors' contributions:

All authors contributed to this project and article equally. All authors read and approved the final manuscript.

\section{References:}

1) Cho YS, Choi MG, Jeong JJ, Chung WC, Lee IS, Kim SW, et al. Prevalence and clinical spectrum of gastroesophageal reflux: a population-based study in Asan-si, Korea. Am J Gastroenterol. 2005; 100(4): 747-53. doi: 10.1111/j.1572-0241.2005.41245.x. PMID: 15784014.

2) Differential diagnosis in primary care. Philadelphia: Wolters Kluwer Health/Lippincott Williams \& Wilkins; 2008: 211. ISBN 0-7817-6812-8.

3) heartburn" at Dorland's Medical Dictionary.

4) Meyer KC. Gastroesophageal reflux and lung disease. Expert Rev Respir Med. 2015; 9(4): 383-5. doi: 10.1586/17476348.2015.1060858. PMID: 26104973.

5) Kahrilas PJ, Shaheen NJ, Vaezi MF. American Gastroenterological Association Institute technical review on the management of gastroesophageal reflux disease. Gastroenterology. 2008; 135(4): 1392-413, 1413.e1-5. doi: 10.1053/j.gastro.2008.08.044. PMID: 18801365.

6) Sonnenberg A, El-Serag HB. Clinical epidemiology and natural history of gastroesophageal reflux disease. Yale J Biol Med. 1999; 72: 81-92. PMID: 10780569, PMCID: PMC2579001.

7) Wahlqvist P. Symptoms of gastroesophageal reflux disease, perceived productivity and health related quality of life. Am J Gastroenterol. 2001; 96(Suppl): S57-61. doi: 10.1016/S0002-9270(01)02590-4.

8) Bloom BS, Jayadevappa R, Wahl P, Cacciamanni J. Time trends in cost of caring for people with gastroesophageal reflux disease. Am J Gastroenterol. 2001; 96(Suppl): S64-9. doi: 10.1016/S00029270(01)02587-4.

9) Dore MP, Pedroni A, Pes GM, Maragkoudakis E, Tadeu V, Pirina P, et al. Effect of antisecretory therapy on atypical symptoms in gastroesophageal reflux disease. Dig Dis Sci. 2007; 52(2): 463-8. doi: 10.1007/s10620-006-9573-7. PMID: 17211695.

10) Moretto EN, Wee B, Wiffen PJ, Murchison AG. Interventions for treating persistent and intractable hiccups in adults. Cochrane Database Syst Rev. 2013; (1): CD008768. doi: 10.1002/14651858.CD008768.pub2. PMID: 23440833.

11) Wong BC, Kinoshita Y. Systematic Review on Epidemiology of Gastroesophageal Reflux Disease in Asia. Clin Gastroenterol Hepatol. 2006; 4(4): 398-407. doi: 10.1016/j.cgh.2005.10.011. PMID: 16616342.

12) Kumar S, Shivalli S. Prevalence, Percep-tions and Profile of Gastroesophageal Reflux Disease in a Rural Population of North Bihar. Natl J Community Med. 2014; 5(2): 214-8.

13) Al-Humayed SM, Mohamed-Elbagir AK, Al-Wabel AA, Argobi YA. The Changing Pattern of Upper Gastro-Intestinal Lesions in Southern Saudi Arabia: An Endoscopic Study. Saudi J Gastroenterol. 2010; 16(1): 35-7. doi: 10.4103/1319-3767.58766. PMID: 20065572, PMCID: PMC3023100. 
14) Wang HY, Leena KB, Plymoth A, Hergens MP, Yin L, Shenoy KT, et al. Prevalence of gastro-esophageal reflux disease and its risk factors in a community-based population in southern India. BMC Gastroenterol. 2016; 16: 36. doi: 10.1186/s12876-016-0452-1. PMID: 26979399, PMCID: PMC4791779.

15) El-Serag HB, Sweet S, Winchester CC, Dent J. Update on the epidemiology of gastro-oesophageal reflux disease: a systematic review. 2014; 63(6): 871-80. doi: 10.1136/gutjnl-2012-304269. PMID: 23853213, PMCID: PMC4046948.

16) Nouraie M, Radmard AR, Zaer-Rezaii H, Razjouyan H, Nasseri-Moghaddam S, Malekzadeh R. Hygiene could affect GERD prevalence independently:a population-based study in Tehran. Am J Gastroenterol. 2007; 102: 1353-60. doi: 10.1111/j.1572-0241.2007.01208.x. PMID: 17437507.

17) Nasseri-Moghaddam S, Mofid A, Ghotbi MH, Razjouyan H, Nouraie M, Ramard AR. et al. Epidemiological study of gastro-oesophageal reflux disease: reflux in spouse as a risk factor. Aliment Pharmacol Ther. 2008; 28: 144-53. doi: 10.1111/j.1365-2036.2008.03708.x. PMID: 18410559.

18) Aletaha N, Pourshams A, Nouraie M, Malekzadeh R. The Role of Psychosocial Disorders in Gastroesophageal Reflux Disease. Govaresh. 2007; 12: 92-7.

19) Prado JP, Moraes-Filho; Chinzon D; Jaime Natan Eisig; Claudio L. Hashimoto; Schlioma Zaterka. Prevalence of heartburn and gastroesophageal reflux disease in the urban Brazilian population. Arq Gastroenterol. 2005; 42(2).

20) Jung HK. Epidemiology of gastroesophageal reflux disease in Asia: a systematic review. J Neurogastroenterol Motil. 2011; 17: 14-27. doi: 10.5056/jnm.2011.17.1.14. PMID: 21369488, PMCID: PMC3042214.

21) Butt AK, Hashemy I. Risk factors and prescription patterns of gastroesophageal reflux disease: HEAL study in Pakistan. J Pak Med Assoc. 2014; 64(7): 751-7. PMID: 25255580.

22) He J, Ma X, Zhao Y, Wang R, Yan X, Yan H, et al. A population-based survey of the epidemiology of symptom-defined gastroesophageal reflux disease: the Systematic Investigation of Gastrointestinal Diseases in China. BMC Gastroenterology. 2010; 10: 94. doi: 10.1186/1471-230X-10-94. PMID: 20707933, PMCID: PMC2933714.

23) Saberi-Firoozi M, Khademolhosseini F, Yousefi M, Mehrabani D, Zare N, Heydari ST. Risk factors of gastroesophageal reflux disease in Shiraz, southern Iran. World J Gastroenterol. 2007; 13: 5486-91. doi: 10.3748/wjg.v13.i41.5486. PMID: 17907293, PMCID: PMC4171284.

24) Kang MS, Park DI, Oh SY, Yoo TW, Ryu SH, Park JH, et al. Abdominal obesity is an independent risk factor for erosive esophagitis in a Korean population. J Gastroenterol Hepatol. 2007; 22: 1656-61. doi: 10.1111/j.1440-1746.2006.04518.x. PMID: 17845694.

25) Kim N, Lee SW, Cho SI, Park CG, Yang CH, Kim HS, et al. The prevalence of and risk factors for erosive oesophagitis and non-erosive reflux disease: a nationwide multicentre prospective study in Korea. Aliment Pharmacol Ther. 2008; 27: 173-85. doi: 10.1111/j.1365-2036.2007.03561.x. PMID: 17973646.

26) Kaji M, Fujiwara Y, Shiba M, Kohata Y, Yamagami H, Tanigawa T, et al. Prevalence of overlaps between GERD, FD and IBS and impact on health-related quality of life. J Gastroenterol Hepatol. 2010; 25: 1151-6. doi: 10.1111/j.1440-1746.2010.06249.x. PMID: 20594232.

27) Mohammed I, Nightingale P, Trudgill NJ. Risk factors for gastro-oesophageal reflux disease symptoms: a community study. Aliment Pharmacol Ther. 2005; 21: 821-7. doi: 10.1111/j.1365-2036.2005.02426.x. PMID: 15801917.

28) Kotzan J, Wade $\mathrm{W}, \mathrm{Yu}$ HH. Assessing NSAID prescription use as a predisposing factor for gastroesophageal reflux disease in a Medicaid population. Pharm Res. 2001; 18: 1367-72. doi: 10.1023/A:1013010616496. PMID: 11683254.

29) Saberi-Firoozi M, Khademolhosseini F, Yousefi M, Mehrabani D, Zare N, Heydari ST. Risk factors of gastroesophageal reflux disease in Shiraz, southern Iran. World J Gastroenterol 2007; 13: 5486-91. doi: 10.3748/wjg.v13.i41.5486. PMID: 17907293, PMCID: PMC4171284.

30) Sharma PK, Ahuja V, Madan K, Gupta S, Raizada A, Sharma MP. Prevalence, severity, and risk factors of symptomatic gastroesophageal reflux disease among employees of a large hospital in northern India. Indian J Gastroenterol. 2011; 30: 128-34. doi: 10.1007/s12664-010-0065-5. PMID: 21061110.

31) Bhatia SJ, Reddy DN, Ghoshal UC, Jayanthi V, Abraham P, Choudhuri G, et al. Epidemiology and symptom profile of gastroesophageal reflux in the Indian population: report of the Indian Society of Gastroenterology Task Force. Indian J Gastroenterol. 2011; 30: 118-27. doi: 10.1007/s12664-011-0112-x. PMID: 21792655. 
32) Locke GR 3rd, Talley NJ, Fett SL, Zinsmeister AR, Melton LJ 3rd. Risk factors associated with symptoms of gastroesophageal reflux. Am J Med. 1999; 106(6): 642-9. doi: 10.1016/S0002-9343(99)00121-7. PMID: 10378622 .

33) Lagergren J, Bergstrom R, Lindgren A, Nyren O. Symptomatic gastroesophageal reflux as a risk factor for esophageal adenocarcinoma. N Engl J Med. 1999; 340(11): 825-31. doi: 10.1056/NEJM199903183401101.

34) Diaz-Rubio M, Moreno-Elola-Olaso C, Rey E, Locke GR 3rd, Rodriguez-Artalejo F. Symptoms of gastrooesophageal reflux: prevalence, severity, duration and associated factors in a Spanish population. Aliment Pharmacol Ther. 2004; 19(1): 95-105. doi: 10.1046/j.1365-2036.2003.01769.x.

35) Locke GR 3rd, Talley NJ, Fett SL, Zinsmeister AR, Melton LJ 3rd. Prevalence and clinical spectrum of gastroesophageal reflux: a population-based study in Olmsted County, Minnesota. Gastroenterology. 1997; 112: 1448-56. doi: 10.1016/S0016-5085(97)70025-8. PMID: 9136821.

36) Isolauri J, Laippala P. Prevalence of symptoms suggestive of gastro-oesophageal reflux disease in an adult population. Ann Med. 1995; 27: 67-70. doi: 10.3109/07853899509031939. PMID: 7742002. 